\title{
Nutrition in the surgical patient
}

Judith A. Vestrup MD FRCPC

\begin{abstract}
Malnutrition is a frequent concomitant of surgical illness. Indeed, several surveys have shown that proteincalorie malnutrition is present in about 50 per cent of surgical patients. ${ }^{1,2}$ Furthermore, in those patients identified as severely malnourished preoperatively, the incidence of post-surgical complications has been identified as being up to six times that of well-nourished patients. ${ }^{3}$ If one adds to this group those patients presenting with normal nutritional status who, because of trauma or sepsis become hypermetabolic and hypercatabolic, the magnitude of the challenge of surgical nutrition becomes clear.
\end{abstract}

\section{Effects of malnutrition on the surgical patient}

The impact of malnutrition is widespread. Many aspects of immune function are adversely affected, including intracellular bacterial killing by neutrophils, absolute $T_{4}$ helper cell numbers and function, complement levels and reticulo-endothelial cell activity. Wound healing is impaired and this is reflected in an increased incidence of wound dehiscence and anastomotic breakdown. ${ }^{4}$ In addition to these general effects of malnutrition, there are also striking changes in cardiorespiratory function. Myocardial mass is reduced, reflected histologically in muscle fibre atrophy and even frank myofibrillar degeneration. As a result stroke volume and cardiac output are decreased. Since starvation results in decreased oxygen consump-

TABLE I Objective tests of nutritional status

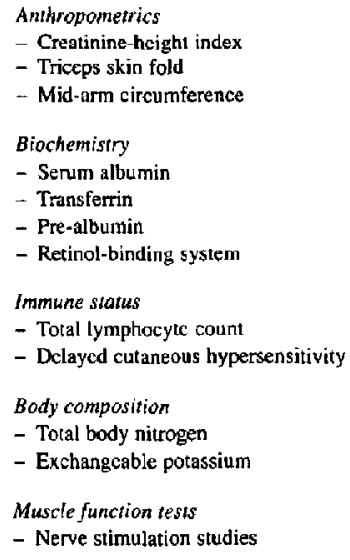

tion some of these changes may simply be adaptive. However, there is the potential for cardiac dysfunction in the malnourished patient with superimposed surgical stress or sepsis. The implications of cardiac cachexia for patients undergoing cardiac surgery as well as the problems of refeeding have recently been well reviewed. ${ }^{5.6}$

In terms of the respiratory system, malnutrition also has a multifactorial impact. ${ }^{7}$ Hypoxic ventilatory drive is diminished, as is vital capacity. Surfactant production is decreased and hence maintenance of functional residual capacity is impaired. In addition to the general affects of starvation on immune function, secretory IgA concentration and pulmonary alveolar macrophage functions are diminished. Also, diaphragm muscle mass and contractility are reduced in the underweight paticnt. ${ }^{8}$ Not surprisingly, therefore, pulmonary complications such as pneumonia and respiratory failure are common.

\section{Indications for nutritional support}

Commonly accepted indications for nutritional support are:

1 Ten per cent or greater reduction in lean body mass,

2 An anticipated period of nothing per mouth $\geq 4-5$ days,

3 Stress state resulting in hypermetabolism and hypercatabolism.

\section{Nutritional assessment}

Although a wide variety of objective nutritional assessment tools is available (Table I), a careful history of weight loss, changes in appetite, and GI tract disturbances combined with physical examination have been shown to correlate well with more objective tests of nutritional status. ${ }^{9}$ In this study, patients graded on clinical grounds as having severe malnutrition had a significant increase in infections as compared to those who were deemed to have normal nutrition. There is one caveat, however, to the use of clinical asscssment alone and this concems the morbidly obese patient. Shizgal et al., ${ }^{10}$ using body consumption studies have shown an 18 per cent incidence of protein malnutrition in this population. Therefore, the possibility of underlying protein mainutri-

Department of Surgery, University of British Columbia, Intensive Care Unit, Vancouver General Hospital, 855 West 12th Avenue, Vancouver, British Columbia V5Z 4E3. 
TABLE II Enteral feeding products - Vancouver General Hospital ICU 1986

\begin{tabular}{|c|c|c|c|c|c|c|}
\hline Formula & $K \mathrm{cal} \cdot \mathrm{m} l^{-1}$ & Osmolality & $\begin{array}{l}\text { Nitrogen } \\
8 \cdot L^{-1}\end{array}$ & $\begin{array}{l}\text { Na } \\
M q_{-} L^{-1}\end{array}$ & $\begin{array}{l}K \\
m E q \cdot L^{-1}\end{array}$ & \\
\hline \multicolumn{7}{|c|}{ Meal-replacement } \\
\hline Osmolite $\mathrm{HN}^{\circ}$ & 1.06 & 310 & 7.1 & 40.4 & 40.0 & $\begin{array}{l}\text { - standard formula for stressed patients } \\
\text { - isotonic } \\
\text { - suitable for jejunal feeding }\end{array}$ \\
\hline \multicolumn{7}{|l|}{ Calorie-dense } \\
\hline Ensure Plus & 1.50 & 600 & 8.8 & 47.8 & 48.6 & $\begin{array}{l}\text { - more nutrition in less volume for hypermeta- } \\
\text { bolic or fluid restricted patients } \\
\text { - hyperosmolar }\end{array}$ \\
\hline Magnacal & 2.00 & 590 & 11.2 & 44.0 & 32.0 & $\begin{array}{l}\text { - for volume restricted patients, tower potassium } \\
\text { - hyperusinolar }\end{array}$ \\
\hline \multicolumn{7}{|c|}{ Chemically defined } \\
\hline Vital HN & 1.00 & 460 & 6.7 & 20.0 & 34.0 & $\begin{array}{l}\text { - elemental formula for patients with malubsorp- } \\
\text { tion, maldigestion disorders (pancreatitis, SBS, } \\
\text { severe IBD. fislulae) } \\
\text { - more expensive } \\
\text { - moderately hyperosmolar }\end{array}$ \\
\hline \multicolumn{7}{|l|}{ Added fibre } \\
\hline Enrich" & 1.10 & 480 & 6.4 & 370 & 40.0 & $\begin{array}{l}\text { - for paticnts on long term tube feeding who may } \\
\text { benefit from added fibre } \\
\text { - slowly advance strength then volume } \\
\text { - initially abdominal distention and flatus may } \\
\text { occur } \\
\text { - contains } 14 \mathrm{~g} \text { dietary fibre/litre (soy } \\
\text { polysaccharides) }\end{array}$ \\
\hline
\end{tabular}

tion in the obese patient, who may appear to most observers to be more than adequately nourished, should always be considered.

\section{Feeding routes}

Once it is established that nutritional support is required, consideration should next be given to determining the route of administration. Enteral feeding should be used whenever possible. It has the advantages of being cheaper and more physiological than total parenteral nutrition (TPN). Small-bore silastic feeding tubes can be placed via the nasogastric or nasoduodenal route and are comfortable and well-tolerated by patients. Alternative routes for enteral feeding are surgically placed gastrostomy or jejunostomy tubes. Newer techniques permit the percutaneous insertion of feeding gastrostomy tubes with the use of upper GI endoscopy. " Feeding tubes placed distal to the pylorus should be used for patients in whom airway protection is a problem, to reduce the risk of reflux and aspiration. In our experience, enteral feeding is feasible even in critically ill patients and, in fact, over 80 per cent of our ICU patients are supported enterally. There is also preliminary evidence in a burn injury rat model that early enterogastric feeding results in less weight loss and better preservation of gut mass compared with intravenuus feeding ${ }^{12}$ It is theorized that preserving gut mucosal integrity reduces bacterial translocation across the gut wall, thereby attenuating the hypermetabolic response.

TPN should be used when the GI tract is not accessible or is functioning poorly. In patients with severe inflammatory bowel disease a period of TPN to permit "bowel rest" may be of value. TPN may take the form of peripheral intravenous nutrition in patients with modest protein-calorie requirements, particularly when only a short course of support is anticipated. For hypercatabolic, hypermetabolic patients, or patients requiring long-term TPN, central access becomes necessary. For this purpose, a percutaneously placed, silastic or polyurethane catheter is employed. For long-term use, a tunnelled silastic catheter (Broviac ${ }^{(1)}$ or Hickman ${ }^{(\mathbb{P})}$ ) is preferred.

\section{Feeding solutions, protocols and complications}

The principles of enteral feeding include:

1 Selection of an enteral formula suitable to the patient's needs (Table II).

2 Commencement of formula at an isotonic strength and a slow hourly ratc.

3 A gradual increase in the concentration or volume of the feed at 12-24 hour intervals. 
4 Final feeding volume should provide for the estimated calorie and nitrogen requirements of the patient.

5 Use of continuous feeding (either by gravity or pump), to reduce risk of aspiration and dumping.

For patients with unique requirements, such as medium chain triglycerides or high nitrogen intake, a modular diet can be prepared with the assistance of an experienced nutritionist. The major problems encountered with enteral feeding are poor gastric emptying and diarrhoea. A trouble-shooting protocol is invaluable in minimizing these complications (Table III). Inadvertent malposition of the feeding tube can be avoided by obtaining $x$-ray confirmation of tube placement before feeding is begun.

Macronutrient calorie sources for TPN are hypertonic glucose and lipid. Lipid solutions available are soy-bean and/or safflower oil based and are marketed as 10 or 20 per cent mixturcs. These contain $1.1 \mathrm{Kcal} \cdot \mathrm{ml}^{-1}$ and $2.0 \mathrm{Kcal} \cdot \mathrm{ml}^{-1}$ respectively and are nearly isotonic compared with 50 per cent glucose which has an osmolality of $2526 \mathrm{mosm} \cdot \mathrm{kg}^{-1}$. Intravenous glucose solutions provide $3.4 \mathrm{Kcal} \cdot \mathrm{g}^{-1}$ of glucose. The complications of TPN can be divided into technical, septic, and metabolic categories. Technical complications include all the potential complications of achieving central venous access, with the additional risks of thrombosis of the great veins, catheter dislodgement and embolization. Infectious complications are most commonly due to gram positive organisms, $\mathrm{S}$. aureus and $\mathrm{S}$. epidermis, and fungi such as Candida. In the neutropenic host, a variety of less common pathogens can also be responsible for catheter sepsis. Metabolic complications include hyper- and hypoglycaemia and electrolyte imbalance, cholestatic jaundice, essential fatty acid deficiency and, if micronutrient needs are not met, a variety of vitamin and trace mineral deficiency states. This topic has been reviewed in detail. ${ }^{4,13,14}$

\section{Prescribing macronutrients for the starvation- adapted and the stressed patient}

Determining optimal calorie-nitrogen intake requires an understanding of the differences between the "starvationadapted" and the stressed, critically ill patient. The chronically malnourished individual is "starvation adapted" in that nitrogen losses are minimized and energy expenditures are reduced to below normal values. By contrast, the critically ill individual has increased nitrogen losses and an increased energy expenditure. Catecholamine, glucagon and cortisol levels are high. Hepatic gluconeogenesis proceeds at an accelerated rate, despite peripheral hyperglycemia and undesirable muscle catabolism takes place to meet the demand for increased amounts of gluconeogenic amino acids. The "starvation-adapted" patients responds predictably to exogenous substrate administration with a gratifying improvement in nitrogen and energy
TABLE III Enteral feeding trouble-shooting protocol - Vancouver General Hospital ICU/Bum Unit

Poor gastric emptying (high residuals)

- If no contraindications, start on metoclopramide (Maxeran $\left.{ }^{2}\right) 10 \mathrm{mg}$ IV a 6 hours.

- Consider changing to a naso-jejunal tube (Cartmil|\$). Administer $10 \mathrm{mg}$ IV Maxeran 30 minutes before tube placement. In most patients the tube will pass through the pylorus within $24-36$ hours. If it does not, endoscopic or fluoroscopic placement may be required.

- Rule out severe hyponagnesaemia or hypoproteinaemia as a cause for gastric ileus.

\section{Diarrhoea}

- Check equipment is clean and formula is not contaminated.

- Rule out impaction causing overflow incontinence.

- Check that patient is not receiving metoclopramide.

- Consider other medications or antibiolics that may cause diamhuea. Also, hypoalbuminaemia $(<2.5 \mathrm{gm} \%$ albumin) may contribute to poor absorption of formula.

- If diarrhoea continues, reduce fecd concentration (i.e., ful] strenghth to $\frac{1}{2}$ strength)

- Persistent diarrhoea requires re-assessment to nule out subacute bowel obstruction, gut ischaemia, pseudomembranous colitis (obtain abdominal $x$-rays, stool for C\&S. C, difficile culture and toxins, consider sigmoidoscopy).

- If no other cause for diarrhoea is found consider adding codeine, Imodium ${ }^{6}$ or Lomotil ${ }^{*}$. Addition of a bulk laxative ar a high fibre formula may also be tried. Discontinue feed only as a last resort.

balance. Such is not the case with a septic or traumatized patient. Burke et al. ${ }^{13}$ have shown that increasing glucose infusion rates above $5 \mathrm{mg} \cdot \mathrm{kg}^{-1} \cdot \mathrm{min}^{-1}$ in burn patients does not increase glucose oxidation or protein synthesis. Rather, the respiratory quotient increases and fatty liver infiltrates are observed. The increased $\mathrm{CO}_{2}$ production shown in stressed patients with hypercaloric glucose infusion may also contribute to the development of respiratory failure or difficulty in weaning from mechanical ventilation. ${ }^{16-18}$ In advanced degrees of stress, particularly scpsis, lipid clearance and utilization is also impaired ${ }^{19}$ and indeed, ultimately branched chain amino acids become utilized as an energy source. ${ }^{20}$ This phenomenon, referred to as "sequential fuel failure" has lead to an interest in other energy sources in severe sepsis. ${ }^{21}$

A commonly used method for estimating caloric requirements is the Harris-Benedict cquation for determining basal energy expenditure (BEE):

$$
\begin{aligned}
\text { BEE (male) }=66 & +13.7 \text { (weight in } \mathrm{kg} \text { ) } \\
& +5 \text { (height in } \mathrm{cm})-6.8 \text { (age in } \mathrm{yr}) \\
\text { BEE (female) }= & 655+9.6 \text { (weight in } \mathrm{kg}) \\
+ & 1.8 \text { (height in } \mathrm{cm})-4.7 \text { (age in } \mathrm{yr})
\end{aligned}
$$

In the chronically depleted patient, repletion can then he accomplished by feeding approximately 1.5 times the resting energy expenditure (REE $=$ BEE $\times 1.1)$. In the 
stressed patient, if at all possible REE should be measured, using indirect calorimetry. For this purpose, systems for continuous expired gas analysis such as the Metabolic Measurement Cart (Sensor Medics ${ }^{(i)}$ ) and the

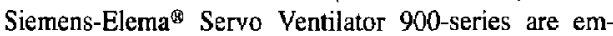
ployed. Use of these systems in ventilator-dependent patients requires great care to obtain accurate, steadystate, reproducible data. ${ }^{22}$ For example, at high inspired $\mathrm{O}_{2}$ concentrations ( $\left.\mathrm{FIO}_{2} \geq 0.5-0.6\right)$ oxygen consumption may not be accurate. Recent experience with indirect calorimetry in critically ill patients has led to the conclusion that total energy expenditure in stress is not as greatly increased as previously thought. In fact, in patients who are sedated and at rest, energy expenditure may be lower than predicted from the Harris-Benedict equation. Alternatively, septic and traumatized patients may have energy expenditures exceeding those predicted. ${ }^{23}$

In practical terms, critically ill patients can most safely be fed using a mixed fuel source (50:50 glucose:lipid) to meet energy needs. Ideally REE should be measured with indirect calorimetry. If the respiratory quotient exceeds 1.0 , suggesting net lipogenesis or if $\mathrm{CO}_{2}$ production increases, glucose intake should be reduced. If indirect calorimetry is not available, it is usually safe to target calorie intake at predicted Harris-Benedict REE. If the latter approach is used, minute ventilation and $\mathrm{pCO}_{2}$ should be followed. An increase in either of these parameters may reflect "overfeeding" with an excess of glucose calories. To monitor lipid clearance, triglyceride levels or clearance studies should be performed at regular intervals.

Positive nitrogen balance can be obtained in unstressed chronically malnourished patients with $0.1 \mathrm{~g}$ to $0.15 \mathrm{~g}$ nitrogen $\cdot \mathrm{kg}^{-1}$. In stress, it is recommended that nitrogen intake be increased to $0.3 \mathrm{~g}$ to $0.5 \mathrm{~g}$ nitrogen $\cdot \mathrm{kg}^{-1} .24$ Even at these high nitrogen intakes, the accelerated protolysis seen in trauma and sepsis may make it impossible to achieve positive nitrogen balance. Use of new enteral and parenteral solutions high in branched-chain amino acid has met with some success in achieving positive nitrogen balance in stressed patients. ${ }^{25,26}$ The recent recognition of a circulating proteolytic factor, ${ }^{27,28}$ which may be interleukin-1 may lead in the future to an ability to attenuate the accelerated proteolysis seen in stress.

\section{Nutrition in the perioperative period}

In preparation for surgery, enteral feeding is usually discontinued six to eight hours preoperatively. If feeding is taking place distal to the pylorus and intra-abdominal surgery is not involved, it is theoretically possible to continue enteral feeding through the perioperative course. Difficulties in monitoring formula infusion rates intraoperatively usually makes this impractical, however.
TPN can and should be maintained intraoperatively. The specific requirements of the TPN patient intraoperatively are:

1 Maintenance of line patency:

- infusion pumps

- avoid admixture of anaesthetic drugs with TPN solutions

2 Prevention of hypoglycemia:

- maintain preop infusion rates

- do not discontinue hypercaloric glucose infusion

- monitor with Glucometer q 1-2 hours

3 Maintenance of strict aseptic technique

\section{Other considerations}

Efforts should be made to maintain normal body temperature intraoperatively, thereby minimizing shivering, $\mathrm{CO}_{2}$ production and proteolysis postoperatively. ${ }^{29}$ It has also recently been shown that TPN can alter rates of hepatic drug oxidation. ${ }^{30,31}$ More investigation will be required before any modifications of drug therapy are recommended.

\section{References}

1 Bistrian BR, Blackburn GL, Hallowell E, Heddle R. Protein status of general surgical patients. JAMA 1974; 230: 858-60

2 Hill GL, Pickford I, Young GA et al. Malnutrition in surgical patients. Lancet 1977; 1: 689-92.

3 Buzby GP, Mulien JL, Matthews DC, Hobbs CL, Rosato $E F$. Prognostic nutritional index in gastrointestinal surgery. Am J Surg 1980; 139: 160-7.

4 Willatts $S M$. Nutrition. Br J Anaesth 1986; 58 : 201-22.

5 Heynsfield $S B$. Nutrition and the heart. An update (Editorial). Nutrition in Clinical Practice 1986; 81-2.

6. Webb JG, Kiess MC, Chan-Yan CC. Malnutrition and the heart. Can Med Assoc J 1986; 135: 753-8.

7 Askanazi J, Weissman C. Rosenbaum SH er al. Nutrition and the respiratory system. Crit Care Med 1982; 10: 16372 .

8. Rochester DR, Esau SA. Malnutrition and the respiratory system. Chest 1984; $85: 411-4$.

9 Baker JP. Detshy AS, Wesson DE et al. Nutritional assessment. A comparison of clinical judgment and objective measurements. N Engl J Med 1982; 306: 969-72.

10 Shizgal HM, Forse RA, Spanier AH, MacLean LD. Pratein malnutrition following intestinal bypass for marbid obesity. Surgery 1979; 86: 60-9.

11 Strodel WE, Lemmer J, Eckhauser F, Botham M, Dent T. Early experience with endoscopic percutaneous gastrostomy. Arch Surg 1983; 118: 449-53.

12 Alexander JW. Nutrition and infection. Arch Surg 1986; 121: $966-72$ 
13 Sheldon $G F$, Baker $C$. Complications of nutritional support. Crit Care Med 1980; $8: 35-7$.

14 Michel L. Serrano A, Mall RA. Nutritional support of hospitalized patients. N Engl J Med 1981; 304: 1147-52.

15 Burke JF, Wolfe RR, Mullany CJ, Mathews DE, Bier DM. Glucose requirements following burn injury. Ann Surg 1979; 190: 274-85.

16 Askanazi J, Rosenbaum SH, Hyman AI, Silverberg $P A$, Milic-Emili $J$, Kinney $J M$. Respiratory changes induced by the large glucose loads of total parenteral nutrition. JAMA $1980 ; 243 ; 1444-7$.

17 Covelli HD, Black JW, Otsen MS, Beekman JF.

Respiratory failure precipitated by high carbohydrate loads. Ann Int Med 1981; $95 ; 579-81$.

18 Biebuyck JF. Total parenteral nutrition in the perioperative period - a time for caution? Anesthesiology 1981; 54: 360-3.

19 Lindholm $M$, Rossner $S$. Rate of elimination of the intralipid fat emulsion from the circulation in ICU patients. Crit Care Med 1982; 10: 740-6.

20 Cerra FB, Siegel JH, Coleman B, Border JR, McMenamy $R R$. Septic autocannibalism: a failure of exogenous nutritional support. Ann Surg 1980; 192: 570-4.

21 Birkhahn RH, Border $J R$. Alternate or supplemental energy sources. JPEN 1981; 5; 24-31.

22 Damask MC, Weissman C, Askanazi J, Hyman AI, Rosenbaum SH, Kinney JM. A systematic method for validation of gas exchange measurements. Anesthesiology 1982; 57 : 213-8.

23 Weissman C, Kemper M, Askanazi J, Hyman AI, Kinney $J M$. Resting metabolic rate of the critically ill patient: measured versus predicted. Anesthesiology 1986; 64: 673-9.

24 Elwyn $D H$. Nutritional requirements of adult surgical patients. Crit Care Med 1980; 8: 9-20.

25 Cerra FB, Upson D. Angelico $R$ et al. Branched chains support postoperative protein synthesis. Surgery 1982; 92 : 192-9.

26 Cerra FB, Shronts EP, Konstantinides $N$ et al. Enteral feeding in sepsis: a prospective, randomized, double-blind trial. Surgery $1985 ; 98: 632-9$.

27 Clowes GH, George BC, Villee CA, Saravis CA. Muscle proteolysis induced by a circulating peptide in patients with sepsis or trauma. N Engl J Med 1983; 308: 545-52.

28 Baracos $V$, Rodemann HP, Dinarello $C A$, Goldberg $A L$. Stimulation of muscle protein degradation and prostaglandin $\mathrm{E}_{2}$ release by leukocytic pyrogen (Interleukin-1). $\mathrm{N}$ Engl J Med 1983; 308: 553-8.

29 Carli $F$, Itiaba $K$. Effect of heat conservation during and after major abdominal surgery or muscle protein breakdown in elderly patients. Br I Anaesth 1986; 58: 502-7.

30 Pantuck EJ, Pantuck CB, Weissman C, Askanazi J, Conney $A H$. Effects of parentcral nutritional regimens on oxidative drug metabolism. Anesthesiology 1984;60: $534-6$.
31 Vesell ES, Biebuyck $J F$. New approaches to assessment of drug disposition in the surgical patient (Editorial). Anesthesiology 1984; 60: 529-33. 